\title{
Semiotic Analysis of Prominent Myths of the Movie "Qeysar"
}

\author{
Marzieh Sharghi ${ }^{1}$, Ebrahim Fayyaz ${ }^{2} \&$ Masoud Kausari ${ }^{2}$ \\ ${ }^{1} \mathrm{PhD}$ Student, Culture and Communication, International University of Imam Reza (AS), Iran \\ ${ }^{2}$ Member of Faculty, Faculty of Social Sciences, Tehran University, Iran \\ Correspondence: Marzieh Sharghi, PhD student, Culture and Communication, International University of Imam \\ Reza (AS), Iran. E-mail: msharghi6@gmail.com
}

Received: September 8, 2016

doi:10.5539/ass.v12n11p93
Accepted: October 8, $2016 \quad$ Online Published: October 14, 2016

URL: http://dx.doi.org/10.5539/ass.v12n11p93

\begin{abstract}
Myths play an important role in our understanding of the general and specific phenomena around. The myth of a nation with the general characteristics and their details are reflective, commentators and unique image that people have discovered. Thus, the study of myth, for both the individual and society both in terms of human culture, is very important. In this article, movie "Qeysar" by Masoud Kimiaee examined in terms of the myth and with the help of the application of semiotics myths enjoying great views of Freud, Jung, Roland Barthes and Mircea Eliade, we have analyzed.
\end{abstract}

Keywords: myth, audience, semiotics, mythology, unconscious

\section{Introduction}

In the works of literary, cinematic, art, advertising, the use of myths or mythical concepts and the extent of its influence on the mind and consciousness, causing the audience adds more relationship will be closer. It cannot do without regard to historical beliefs, heroes, myths, and mythmakers who make up a community mental unconscious message designed and the effect was playing it safe. No doubt aware of the myths used in various works of art, literary, cinematic and achieve deep insight into the type and shape of the myths used in the works and awareness of the impact of mental myths layers audience leave in recognition of the impact of the effect on the audience is very revealing. On the other hand, creators can also with knowledge of the matter important myths a society in different layers of their own work placement and thus increase the effectiveness of their messages to the target audience. Freud and Jung's theories of myth and the unconscious is well represented and semiotic analysis of mythical if very useful. Freud emphasizes on the individual unconscious and Jung emphasis on the collective unconscious. Jung's subconscious mind that is the deepest layers of the human mind forms, "collective unconscious" called.

This general section, collective, impersonal and common to all human beings and through personal awareness, some cases, the behavior and attitudes are typical similar in all of them. Jung's collective unconscious contains a collection of ancient pre-historical experiences. Although this ancient experience is not directly detectable, their impressions of the day which makes it possible to identify them and the archetypes are crystallized (Jung, 1955, p. 157).

According to Jung, myths and archetypes, the collective memory of mankind have a strong presence. These archetypes, themes, images or patterns are similar concepts for a wide range of different cultures induce humanity (Sugg, 1992, p. 65).

\section{Semantics and Meaning of the Word Myth}

The term myth can be found in all European languages, as we know from the Greek mythos in the works of Homer, meaning "speech, talk, speech", and later derived, means "animal tales and myths" spread. The myth is the story of a certain character, a narrative in which the gods have one or more central role. Word vocabulary and literary mythos along with many morphological and syntactic compounds Latin quotes and all forms of the word in the language derived from the Latin words have been taken in Europe. (Strauss, 1998, p. 9) Synonyms mythology in European languages is the word myth in English; mythe in French; myth-e in Germany; the semantic content of the word myth and mythology of the plurality of them in Persian. Apparently, word myth from the original Greek (muthos) was meant to talk about and legends and so-called mythology in European 
languages, the mythology, mythologist and mythology in our language (Mehrdad, 1997, p. 343).

According to Eliade scholars of the 19th century myth in the usual sense of the word, ie the concept of "fable" is story, which quoted in the language of animals and applies human emotions to animals and often aspect ratio allegory. Its emphasis on spiritual and moral concepts, and "invention" (something invented, artificial but exquisite), and "fiction" (poetic fantasy or fiction) were examined.

But the later Western scholars unlike their predecessors, these terms have the same meaning in ancient societies or the old understanding and the meaning that is the concept of "real story" and the autobiographical expression are highly valued and valuable, because sacred, exemplary and meaningful, their perception. In fact, this word means today, fiction or illusion (delusion and illusion or idea) is used, and also means "sacred tradition or divine" original or initial revelation, exemplary model" (Eliade, 1983, pp. 9-10). In English, the word "story" means history and fiction.

The gist of the speech and mythology of the leading contemporary scholar, "Mircea Eliade" lies and it is difficult to define myth that is acceptable to all scholars and according to non-specialists to understand. According to Eliade's definition of myth that the lowest failure is expressed as follows: myth tells a sacred history; the myth of an event that occurred in very ancient times, said (Eliade, pp. 1133-1134).

Sigmund Freud (1939-1856) and his followers myth and a symbol of bio-native schools of psychoanalytic interpretation was unconscious inner mind and root it in human sexual psychophysiology and explain the dynamics of unconscious desires, fears and knew libido (Blockasi, 2000, p. 24).

Ali Shariati also pointed out the origin myths that "the mythology, human need is real history - that fact and realize own again - do not feed him, mythology makes and knows that the mythology is a lie (Shariati, 2003, p. 56).

Professor Fuzuli Bayat (2005) defines myth as a "myth is speculation about the origin of the oldest people in the world and life, natural disasters, gods, mythical heroes and ghosts" (Bayat \& Fuzuli, 2010, p. 43).

\section{Myth Species}

Myths from different perspectives can be subdivided into species. "Sallustius" (Sallust) the material world only knew a big myth it was worth it in the spiritual meaning hidden and revealed, not in him. "Gilbert Murray" (1866-1957), English scientist through multiple effects to the same person essay refers to the name of gods and mythological world in its fifth sample is limited to five kinds. This division, at the same time noted to accepts the interpretation views of metaphor and mythology. Sallustius, some religious mythology, some natural, some mental, some physical (material) and some of the latter two types are mixed and then for each of the examples mentioned (Namdarian, 2005, p. 150).

\section{Myth, Unconscious and Impact on the Audience}

Myths are a big part of your subconscious human mind and to some extent the role of leadership is responsible for their thoughts, as Freud and Jung stressed that what comes from the conscious to the subconscious does not go but by being in the unconscious mind without knowing the formation of character and affect our behavior. Myths are also the same function, they are still alive in the historical memory of our ancestors and the mind and thoughts rule us without our being aware of it. This is especially good when the choice is obvious that humans are exposed, perhaps you have ever asked yourself why the multi-product, message, fiction, drama, poetry, and painting and ... only some of them to draw your attention and if only some of them will be selected as choice, undoubtedly, many factors affect your selection process (Brown, 1942).

According to Freud, thoughts, through representation between conscious and subconscious mind are in circulation. According to him, the meaning of "true" and the literal words are not so important; associations are important. Even the most abstract connotations of certain words from their roots and can also be used to remind a certain connotation. Generally represent conscious and unconscious in different ways. Freud representations of words (word presentation) and representations of the object (thing-presentation) called. Hence, the representation of the unconscious only displays the object.

When we think of semantic meaning for the word entered our minds and at the same time as the object is present in our minds (Istoob, 2011). If the sense of conscious we go out, does not mean that no longer exists. Forgotten your ideas can be recovered. Part of the unconscious, the pool of ideas and passions and representations temporarily deleted, although not present in consciousness effects on it (Jung, 2010, p. 35).

Jung's collective unconscious theory was true. He understood, and explicitly stated that mythical symbols of elements found in the psychological analysis, symbols that are present in the unconscious, as if he inherited. 
According to Jung, there are symbolic elements in our psyche meaning that they are open, and to assist any conventional methods of Freud's psychoanalyzed not recognized. On the contrary, it seems that the elements and meanings born, "meaning the eternal and everlasting". The images survivor, in the fullest and most accurate form a "prototype" are those that appear in many ways symbolic, that is, aesthetic and religious symbols are recreated. San We know this without being in a world of gods, demons, angels, and the presence of good and evil forces of our lives has changed. Jung symbolic elements in fact are unconscious ancestral heritage, which we have been there before birth. We have been born in the collective unconscious, and images that are in many cases only regenerated prototype" (Ahmadi, 1999, pp. 373-369).

"Psychological analysis reveals that artists have always wanted artistic creation stems from the subconscious is very powerful, and surprisingly harsh and authoritarian." He emphasized that the work of art is as a living thing grows inside the mind of the artist, and then offered to everyone, the independent creative. Even the artist will never cease to take effect mechanism of growth and independence. It is perhaps because of the central position of the talk of the unconscious in the creation of art and the artist rather, and especially the artistic visionary role in the development of art in the writings of Jung's analysis that from the 1920s to today, according to his writings on art particle has not diminished (Ahmadi, 1999, p. 365).

He calls the myth collective dream that throughout history, nations have seen it again and figurative language and symbolism have said. In fact, the collective unconscious is the same factor that creates collective symbols. On the other hand, a broader culture, symbols of the collective unconscious reveals the deepest layers. These icons make up the oldest samples in the institutional bodies are shaped and then emerged (Kazazi; 1993, p. 70 ff).

According to Jung, the collective unconscious patterns or images in which there early, saving the collective experience of humankind throughout many ages. The initial images are "the oldest and most pervasive" forms of thought "man. They are feelings and thoughts. In fact, they have their own independent life (Jung, 1953, p. 65).

\section{Myth and Cinema}

Cinema considered as a medium and high impact on the audience in society. McLuhan believes technologies and synergistic effects of a cause and the human senses completely separated from each other. Thus, each of the communication devices is along one of the human senses. As the stones along, bike along the leg, photos along the eye, ear and hearing on the radio and (TV along with the sense of touch), which would ultimately also be a balance between the other senses. He boldly highly thermally communications and it is divided into two categories: In this division (photo, radio, and cinema) knows as a hot means of communication. This relationship means the suites are located along one of the human senses and (pictogram, telephone, television) to a cold reading device (McLuhan, 1997, p. 41).

However, the cinema is a cultural commodity and product of imagination and intelligence, a group of artists is a Media. If it can be said for, poetry or painting because his heart if discontent and destroyed it, it would in the cinema is not possible and reasonable. When a movie and plenty of opportunities to make big capital spending is mobilized, the investor expects (and the expectation is reasonable, of course) that hundreds of thousands of people see the film and principal with profits from its return to its owner (Mohammadi, 1991, p. 41).

Border cinema and cinema as a medium as a promotional tool, there is not predetermined movemaker type of impact on the viewer and have nowhere else to go, he thought (Mohammadi, 1991, p. 43).

Cinema - fundamental properties as an art and film - as a Media and can be generally divided into three categories:

1. Category refers to the movie image and set it as a document of reality or "copies" introduced.

2. A class raises the film as a medium of communication.

3. Category that is related to the experience of watching movies (Jahromy, 2000, p. 150).

\section{Semiotics of Film}

Semiotic theorists believe, there are six of semiotics, the study of its function in understanding the film and its implications is very useful:

1. First category: visual sign system is the most iconic symbol refers to operation.

2. Second category: the system is further indication motor moves the camera, scanning and editing refers cinema.

3. Third category: the linguistic signs that the location of the spoken word, language, speech, conversation and external interpretations in cinema. 
4. Fourth category: the system of linguistic signs written, a large part of the function of writing in the cinema as the film, subtitles to the videos and written symbols within the structure of the film in mind.

5. Fifth category: the phonetic system of non-linguistic signs mostly refers to different forms of sounds and the natural sounds in cinema.

6. Sixth category, the musical symbols, which are part of the soundtrack, music videos and any music in a film (Sarami, p. 6).

\section{Film Summary}

"Fati" by one of the Abmangoll brothers called Mansour, desecrated. "Fati" after writing a letter to his mother and his uncle, the self-destruction and died in hospital. "Farman" big brother Fati, after becoming aware of the issue, goes to the shops Abmangoll brothers and by two brothers Mansour, Rahim and Karim, surprise and killed.

"Qeysar" command little brother, Karim and Rahim in shower in slaughterhouses foot drives. At the time of his burial, help his girlfriend escape from the hands of police and by dancer (Shahrzad) Mansour is at the railway station and he kills himself with a bullet police finally comes down.

\subsection{Symptoms of Legendary Film}

Qeysar film name: name is a work of art, rather than specific code refers to the content of the message and in fact is an indication of the specific nature of the work of art. The title and throughout the movie, succession issues are present in abundance. This focus on the implications of different metaphors with each of the slab remained (Zeimaran, 2003, p. 86). As well as the Eastern Roman Empire (especially) described the Qeysar Roman Emperor Julius as the Roman Empire from his family after he was called to Qeysar title after all Roman emperors were called this name.

In the film named Qeysar is more than just a title and a nickname other words or series features a character that is represented in the film. Qeysar film represents the personal defense and struggle against oppression imposed on a trunk of a hero class is special, he main motive of "honor" is also jealousy (zeal and eyebrows), which provides men the task of "privacy" defend themselves against foreign aggression. This is partly because of the name Qeysar for the film makes clear. In the mind of the audience Qeysar based on a succession of strong-willed person, firm, steadfast, resolute and tireless evokes and manners and chivalry that his man will lead him to achieve a specific purpose and can never ignore an invasion of his privacy even if it meant losing his life.

Qeysar (main character): character in the film is essentially a mythical character; he has the character of a myth in the minds of the audience. In this sense, he can be compared with Rustam Shahnameh and Prometheus of Greek mythology. As Rostam against the Kings, Prometheus stands against the God of gods and Qeysar like the trunk of a stroke rises with the power to wage war. His mythical symbol of the heroes who each community according to the conditions and demands of their own time, like all heroes, mythical knows that death is inevitable fate in this way but the heroic death of the life of humiliation prefered. He is loved and popular among the people and this is due to the special heroic character, he goes in waves. Qeysar is mythical symbol alive and evokes historical heroes of Iranian society.

(Fatemeh) the sister of Qeysar: Qeysar's daughter was raped and sister, "Fatima", the profile of the daughter of the Prophet (S) and symbolizes the honor of the Muslim community. His disrespect is disrespect for all. Fatemeh name in mind, purity, innocence is alive and somehow evokes important and sacred religious myth that insults the memory of that sin is unforgivable.

Eagle and Child: the title, the eagle with talons open, and children like angels in their grip, and in view of the child's other and the knife goes to the Eagle sign. The child symbolizes purity, true-heartedness, and purity and a profile of being blindfolded, quiet and innocent and eagle symbol of power, domination, command and control of the system or rules of society.

Icons legendary evoke, he is the mythical eagle symbol of purity and innocence that makes cruelty and power come to mind. Feeling helpless and innocent children (Qeysar) is transmitted to the audience and revenge of the Eagle (the ruling system time) in him is strength and here again the protagonist puts in place and with all the power of child protection.

Shahnameh: there are various references to Shahnameh throughout the film.

Film begins by displaying tattoos Kings and knights of old. Qeysar film using elements rooted in the beliefs of the ancient Iranians, including (Shahnameh, gymnasium, Khosrow and Shirin) offers concepts related to masculine behavior to the audience. 
Knife: "Knife" is a profile of cruelty, coldness, violence and even anti-morality, religion and tradition. Seven deaths occurred in Qeysar who hit five of them with a knife. Use a knife and lay on the floor of life, the sense of frustration and distrust of cultural ethics and issues of masculinity, honor and honor is mocked.

Qeysar knife concerted interpretation and experience the spirit of the times and the psychology of the younger generation of intellectuals of that era was long and solutions. This was Iranian symbol of the struggle of all those theories and secret letters, legitimacy was rooted. With Qeysar, teen people of the book and the declaration of murder and it were a relief to know his intellectual identity" (Mir Ehsan, 1998).

Cabaret: Cabaret (the most obvious symbol of a passive society and good wines) in the film. A symbol of modern society and the denial of traditions and moral values of a society, Qeysar sequence alone on the ship nightclubs full of dancing and singing and a society full of social blind optimism are palpable and tangible.

\subsection{Semiotics of Film Legend}

In the title of film Shahnameh illustrations that is Rostam, Esfandiar, and Sohrab, Siavash and other symptoms epic is used. Seeing these symptoms as well as the audience discovers that faced with a tragedy tinged with heroism. Credits (credits) Qeysar film of naked human body and tattoos picture on it, the black background is formed. Tattoo includes pictures of the heroes of Shahnameh, which appears in the narrative story using the characters and mythology in the Shahnameh. Multiple references to the Shahnameh in the film Qeysar and especially putting it in front of mirror images of mythical title, it is our Qeysar also put it at odds with Khan's uncle. This contrasts Qeysar and Khan's uncle, old and new conflicts, conflicts of ideals and the fact throughout the film seen. Farman big brother Fati around black dress, white apron Butcher, Shapoee hats arrive, walk ruffian-like look and worry about browser will be accompanied by music gymnasium, and metaphor is based on a succession of athletes and young men in your class society and have enjoyed popularity and respect.

Camera movement with music and a confirmation link between the mythical epic hero and the hero's command. In the third sequence suicide, disclose the content of a girl home with him takes on a new dimension, has raped. Suicide assault in connection with traditional and religious elements, the depth of this tragedy in such an atmosphere the news and the other girl action in defense of the honor, was defenseless and oppressed, to accompany and identification in film and an anti-values action and movement, contrary to religious principles and condemned a matter of justifiable and even laudable cause.

The coffee shop scene, we found a small cafe but we are busy, small community or subculture of a larger community, the cafe did not spend one place, but a combination of locations, dates and times past and experience the characters in the future as well. Coffeehouse was one of the institutions that emerged during the Safavid and Qajar and Pahlavi periods were the peak of prosperity (Blokbashy, 2014, p. 116).

Coffeehouse culture as a social institution as interested in traditional societies functioned in Iran and throughout its centuries-old life, in each time, and due to the social situation in each town with a population and culture and people associated with attitudes and religious beliefs of the people served. Current events in the community that created the cultural movement in line maintain the ethical and behavioral characteristics of generations past and revive and strengthen the spirit of chivalry, gallantry, sacrifice, these traits were interactive and transmission to future generations. Coffeehouse with such functions such as institutional side of the house and family acculturation people in Iranian society and their familiarity with the culture and traditions and the ancient traditions of ethnic and religious Iranians walked (Blokbashy, 2014, p. 116).

Qeysar confessed to the murder sequence, we see that Khan's uncle Shahnameh in front of his face, portrait of a hero with a knife or dagger swallow their anger over another referring again to the metaphor of Shahnameh and that is victory Qeysar over the enemy.

Qeysar nightclubs in the human sequence has only concern is that the big supermarkets and shops colorful and stylish city cars in line and not tangent and nightclubs filled with dancing and singing in his city alone and single Qeysar hunting Mansour entered the cabaret (the most obvious symbol of a passive society and good fruit) leaves (as if his deal with Mansour deals with the society of his days.

The myth of birth and death are featured in the film, Qeysar film, the wheel of death, death, and the death of Qeysar, the birth of man. Sinful man a year later, in 1349, unlike his predecessors took up arms and any means to solve the conflict themselves with the ruling system. Immortality "hero" and the need of the hour to win, death is not aware of who rejects injustice and justice runs its own way.

\section{Conclusion}

Throughout the film of mythic signs and symbols related to Iranian culture is used. The title is taken from the 
type of music used, movie characters, spaces and places where the story takes place and even dialogue all kind of myths or legends are associated. Videos can be distinguished from myth as the movie, the character of Qeysar, Fati, Farman, Shahnameh, Abmangol Brothers, knives, children, eagles and ... pointed out that along with concepts such as death, birth, love, immortality, hatred, violence mythical figure presented itself and merely a simple concept and not normal. Mythical species of religion, personality, cultural heroes and myths of redemption, the myth of rebirth and renewal, the myth of remembering and forgetting more than other species used in the film. Another point in the movie Qeysar is considerable use of forms of ancient Iranian patterns background images.

In other words, in addition to characters, objects and shapes are referred to the various myths or concepts remind them of Shahnameh hero's motifs and designs on the walls of the café, Tattoos on the body of the hero gymnasium, gymnasium music is also included in the sequence, there are various references to the Shahnameh throughout the film. Tattoos of kings and knights of old film begins by showing that further references to the Shahnameh and in this respect the film makes a richer and more influential.

\section{References}

Ahmadi, B. (1999). Truth and beauty. Tehran publications Publishing Center.

Bahar, M. (1997). Research in the mythology of Iran (2nd ed.). Tehran: Sepehr Role.

Barghi, K. J. (2001). Psychology audience in the face of tragedy. Magazine Show, 38\&39.

Bayat, F. (2013). Introduction to Mythology (Mythology Turks). Publishing Helpers.

Blokbashy, A. (2000). The world's leading myth mythology of thought and expression. Art Monthly, 25\&26.

Blokbashy, A. (2014). Coffeehouse in Iran. Tehran: Cultural Research Bureau.

Brown, W. F. (1942). The determination of factors influencing brand choice. New York: The National Convention of the American Marketing Association.

Eliade, M. “Myth”, Encyclopedia Britanica (Vol. 15). Encyclopedia Britanica Inc.

Eliade, M. (1983). landscapes, myths (translated by Jallal Satari). Tehran: Tus.

Interview with Masood Kimiaee. (2011). The documentary "Kaiser forty years later". Massoud Najafi.

Istoob, A. (2011). Unconscious (translation Shiva Rooigarin, 3rd ed.). Tehran: publishing center.

Jung, C. G. (2010). A man and his symbol (translation of Mahmoud Soltanieh). Tehran: Jami Publication.

Jung, C. G. (2012). The psychology of the unconscious (translated by Mohammad Ali Amiri). Cultural Scientific Publishing.

Jung, C. G., \& Pauli, W. (1955). The Interpretation of Natureand the Psyche: Synchronicity: an Acausal Connecting Principle. Pantheon Books.

Kazazi, M. J.-D. (1993). Dreams, epic and myth. Tehran: Publishing Center.

McLuhan, M. (1997). Film and media hot and cold. Cinema Journal, October 24.

Mirehsan, A. (1998). Qeysar forget. Film and cinema, (7).

Mohammadi, M. (1991). TV tuner cinema: cinema, (5).

Namdarian, T. (2005). Stories coded password in Persian literature. Tehran: Institute for Humanities and Cultural Studies.

Shariati, A. (2003). Despite the fact the kind of mythology. Tehran: Amon Publication.

Soleimani Sarami, Z. Semiotic analysis series "Bye Baby". Broadcasting Research Center of Qom.

Strauss, L. (1998). World Mythology (translation Jallal Satari). Tehran: Publication Center.

Sugg, R. P. (1992). Jungian Literary Criticism. Northwestern University Press.

The Collected Works of Jung. C. G. (1953). Two Essays on Analytical Psychology (Vol. 7). (London: Routledge \& Kegan Paul.

Vaheddoost, M. (2002). Scientific approach to mythology. Tehran: Soroush Publications.

Zabeti Jahromy, A. (2000). Film, feature film as a medium. Magazine Art, 44. 


\section{Copyrights}

Copyright for this article is retained by the author(s), with first publication rights granted to the journal.

This is an open-access article distributed under the terms and conditions of the Creative Commons Attribution license (http://creativecommons.org/licenses/by/4.0/). 